\title{
El final de la reconciliación: la politización del pasado reciente en España
}

Sören Brinkmann*

Resumo: No final da década de 1990, a Espanha vivenciou a aparição de um novo movimento sócio-político que luta pelo reconhecimento oficial das vítimas da guerra civil de 1936-1939 e da ditadura do general Franco, entre 1939 e 1974. A questão básica se concentrava no esclarecimento do destino de mais de 30.000 republicanos vítimas de repressão política e que, até hoje, são classificados como "desaparecidos". O surgimento desse movimento coincidiu com o segundo governo do conservador José María Aznar, que rejeitou as demandas das associações cívicas, porque elas, supostamente, contrariavam a política de conciliação que viabilizou o retorno à democracia, na década de 1970 . Mas, em 2004, após terem vencido as eleições gerais, os socialistas espanhóis propuseram uma lei para indenizar as vítimas da repressão franquista. Este artigo analisa as circunstâncias e o processo político por que passou a proposta legislativa, até que fosse aprovada pelo parlamento espanhol, em 2007.

Abstract: At the end of the $1990^{\text {th }}$ Spain saw the emergence of a new sociopolitical movement that fights for an official recognition of the victims of the civil war (1936-1939) and the dictatorship of General Franco (1939-1974). The main issue at stake is the elucidation of the fate of more than 30,000 republicans who fell victim to political repression and who are still today regarded as "disappeared". The emergence of this movement coincided with the second government of the conservative José María Aznar, who rejected the claims of the civic associations as being contrary to the politics of reconciliation that had conditioned the return to democracy in the late $70^{\text {th }}$. However, in 2004 and after having won the general elections, Spanish socialists proposed a draft law to indemnify all the victims of Francoist repression. The article analyses the circumstances and the political process the socialist draft law went through until it finally passed the Spanish parliament in the end of 2007.

Palavras-chave: Guerra civil espanhola. Vítimas. Memória.

Key words: Spanish civil war. Victims. Memory.

* Universidad de Erlangen-Nuremberg, Alemania; e-mail: soeren.brinkmann@wiso. uni-erlangen.de

Estudos Ibero-Americanos, Porto Alegre, v. 35, n. 1, p. 7-23, jan./jun. 2009 


\section{El retorno del pasado reciente}

Cuando en noviembre de 1975, al morir el dictador Francisco Franco, comenzó en España la Transición a la democracia, surgió como en todo proceso de transformación democrática - la cuestión de qué hacer con la carga moral de un pasado de casi 40 años de dictadura. El legado más delicado de la historia reciente lo constituía la memoria de las represiones políticas acaecidas durante la Guerra Civil (19361939) y la posguerra y que estaba aún muy viva en miles de víctimas y de sus familiares. La magnitud de la violencia política se evidencia con toda claridad ante el trasfondo de los 150.000 muertos causados por la propia guerra. La cantidad de víctimas del terror revolucionario en la zona republicana se calcula entre 35.000 hasta 50.000 personas mientras que la cifra de los represaliados en la zona "nacional" asciende a al menos 150.000 personas. A esto hay que añadir entre 200.000 y 400.000 personas del bando republicano que sufrieron durante años en batallones de trabajo forzado y campos de concentración del régimen y casi otro medio millón de refugiados que salieron del país al finalizar la guerra en 1939. Y finalmente, entre los miles de víctimas del franquismo se calcula que hasta hoy día hay alrededor de 30.000 "desaparecidos" de la guerra por haber sido fusilados arbitrariamente y enterrados en fosas anónimas por todo el país. ${ }^{1}$

Para "neutralizar" este tremendo legado histórico las elites políticas de la Transición democrática se sirvieron de la famosa Ley de Amnistía de 1977 basada en un amplio consenso político de todos los partidos y que significó un auténtico "borrón y cuenta nueva" con respecto a la violencia del pasado. Porque la ley no sólo amnistiaba a los presos políticos del régimen franquista sino también declaró impunes todos los crímenes de lesa humanidad cometidos por los verdugos del régimen hasta la muerte del dictador. Y las repercusiones de la ley iban incluso más allá de lo jurídico al reprimir, aunque de manera indirecta, no solamente un debate crítico acerca de las responsabilidades políticas sino también el luto público de los familiares de las víctimas. Con ocasión de la votación parlamentaria del texto todos los grupos se comprometieron a olvidarse de las divisiones y rencores de la Guerra Civil para, de tal manera, garantizar el éxito de la consolidación democrática.

La decisión de silenciar el pasado se basaba en la hipótesis - muy extendida en la sociedad española desde hace mucho tiempo - de una culpa

1 Para una visión global de la represión política en los años 30 y 40 véase JULIÁ, Santos (ed.). Victimas de la guerra civil. Madrid: Ediciones Temas de Hoy, 2006. 
colectiva que recaía en partes iguales en los dos bandos de la guerra y que resultó una precondición indispensable para la reconciliación nacional. Sin embargo, es evidente que esta reconciliación dejó un balance muy desigual con respecto a los "vencedores" y a los "vencidos" de la Guerra Civil dado que el precio para la recuperación de la democracia era mucho mayor para estos últimos. El bando republicano - aparte de haber tenido que soportar la derrota militar y sus consecuencias inmediatas - sufrió represiones mucho mayores así como una prolongada discriminación socio-económica que sólo venía relajándose con el boom económico de los años 60 y la consecuente extensión del bienestar. Y tampoco después de la muerte del dictador el Estado español se esforzó expresamente para reparar las injusticias sufridas por los vencidos. El Gobierno de Felipe González, que subió al poder en 1982 y cuyo partido - el Partido Socialista Obrero Español - había figurado entre los mayores perdedores de la guerra, puso en vigor medidas de reparación muy limitadas. A su vez y con ocasión del cincuentenario del estallido de la Guerra Civil en 1986 el Presidente del Gobierno declaró que "una guerra civil no es un acontecimiento conmemorable, por más que para quienes la vivieron y sufrieron constituyera un episodio determinante en su propia trayectoria biográfica". 2

Este desinterés oficial con respecto a los múltiples sufrimientos de los perdedores fue compensado en cierto modo por la presencia de la historiografía académica que ya desde los años 70 había indagado en las causas sociales y políticas de la Guerra Civil y cuyos resultados invadieron el mercado del libro en forma de un sinfín de nuevos títulos. Pero en estos momentos la historia académica todavía no consiguió enlazar con los protagonistas históricos. ${ }^{3} \mathrm{Y}$ tampoco se hizo patente una urgente necesidad desde la sociedad civil de articular públicamente las memorias de los perdedores de la guerra. Sólo en algunos lugares aislados y después de las primeras elecciones municipales de 1979 llegaron a formarse pequeños grupos de ciudadanos con el fin de defender los derechos de las víctimas, buscar familiares "desaparecidos" y darles una sepultura digna. ${ }^{4} \mathrm{Y}$ ya con el intento de golpe de estado del

2 Citado según BERNECKER, Walther L. Vergangenheitsbewältigung auf spanisch. Die spanische Diskussion zum 50. Jahrestag des Bürgerkriegsbeginns. Tranvía, Berlín, v. 9, p. 17-20, 1988.

3 La única excepción es la obra pionera del historiador británico Ronald Fraser. Véase FRASER, Ronald. Blood of Spain. An Oral History of the Spanish civil war. New York: Lane, 1979.

4 Véase SILVA, Emilio; MACÍAS, Santiago. Las Fosas de Franco. Madrid: Ed. Temas de Hoy, 2003, p. 121 y s. 
23 de febrero de 1981 estas actividades llegaron a un fin abrupto que hizo enmudecer la memoria colectiva de los perdedores durante casi veinte años más.

Ahora bien, desde finales de los años 90 - es decir, precisamente en el momento cuando la generación de la Guerra Civil está desapareciendo definitivamente - comenzó a perfilarse un profundo cambio de la cultura de memoria. En el año 2000 el periodista Emilio Silva fundó en la región de Castilla y León la Asociación para la Recuperación de la Memoria Histórica (ARMH) y exhumó en el pueblo leonés de Priaranza del Bierzo una fosa anónima que, aparte de otros doce esqueletos, también albergaba los restos mortales de su abuelo, asesinado al principio de la Guerra Civil. El ejemplo de Silva levantó la liebre y en poco tiempo surgió en toda España una red de asociaciones privadas cuyos miembros - muchos de ellos familiares de víctimas - reivindicaban medidas de reparación y esclarecimiento histórico. Lo nuevo son los protagonistas de este movimiento que - a diferencia de los años 70 - hoy en día son en su mayoría los nietos de la generación de la guerra.

La proliferación de este movimiento por todo el país coincidió con la segunda legislatura del Gobierno conservador de José María Aznar que al frente del Partido Popular había ganado una mayoría absoluta en las elecciones de 2000. Para los partidos de la oposición, humillados por su derrota electoral, este nuevo movimiento social constituía un buen punto de partida para salir de la defensiva. Así, después de más de 25 años de inactividad en este ámbito, los partidos de izquierda adoptaron las reivindicaciones de las asociaciones cívicas y lanzaron toda una serie de proposiciones de ley dirigidas a reparar las injusticias históricas y condenar el franquismo. Al partido de Gobierno, sin embargo, no le gustaba esta nueva visión del pasado que de hecho venía dirigida a culpabilizar únicamente el bando franquista. Y como consecuencia, los conservadores hicieron fracasar con su mayoría absoluta todas estas propuestas hasta el final de la legislatura.

La inesperada victoria electoral de los socialistas en $2004^{5}$ levantó nuevas esperanzas en las asociaciones de la memoria. José Luis Rodríguez Zapatero, el nuevo Presidente del Gobierno, cuyo abuelo también había caído víctima de los militares rebeldes, prometió medidas

5 En la víspera de las elecciones todas encuestas apuntaban a una victoria del Partido Popular. Pero esta victoria no iba a materializarse dados los atentados islamistas a los trenes de cercanías en Madrid tres días antes de las elecciones que llevaron a un cambio radical de la opinión pública que se saldó con la inesperada victoria del Partido Socialista. 
rápidas para satisfacer las demandas del movimiento. Y en septiembre de 2004 el Gobierno creó una Comisión Interministerial con el cometido de estudiar la situación de las víctimas de la Guerra Civil y proponer medidas de rehabilitación moral y jurídica. A finales de julio de 2006, casi dos años más tarde, la comisión presentó finalmente una proposición de ley cuyo contenido estaba diseñado, evidentemente, a ganarse el apoyo del Partido Popular. Porque en vez de una condena explícita de la dictadura franquista el preámbulo del borrador condenaba todo tipo de violencia como instrumento político y de igual manera el texto se dirigía a todos aquellos que en la historia reciente habían sufrido represiones y persecuciones por motivos políticos. Aunque los perdedores de la guerra continuarían ser los mayores beneficiarios, resultó obvio que el Ejecutivo intentaba de enlazar esta ley con la política de reconciliación para así conseguir un amplio consenso político. ${ }^{6}$

\section{El Partido Popular en la penumbra del franquismo}

Como era de deducir de declaraciones anteriores, todas las concesiones en dirección a los populares no serían bien recibidas. Por el contrario, Mariano Rajoy, el nuevo líder del Partido Popular, calificó los planes del Gobierno como "un enorme error" y reprochó a Zapatero una vez más "abrir viejas heridas" y pretender "revisar" los resultados de la Transición. De un calibre más pesado fue el ataque del antiguo Presidente del Gobierno, José María Aznar, cuando en un acto electoral en la provincia de Zaragoza en mayo de 2007 en referencia a los planes socialistas afirmó: "Zapatero ha conseguido que media España no acepte a la otra media. Y eso, que nos condujo a lo peor de nuestra historia hace 70 años, es el esquema político que se quiere repetir ahora". ${ }^{7}$ La alusión a la Guerra Civil era evidente y así lo interpretaron algunos medios de comunicación. El apogeo picante del asunto fue, sin embargo, que $E l$ Pais, diario cercano al Partido Socialista, fue obligado a rectificar un día después desmintiendo que Aznar hubiera utilizado la palabra "Guerra Civil".

¿Pero por qué se atrincheraba el Partido Popular todavía tan categóricamente contra cualquier tipo de reparación a favor de las

6 Véase al respecto Consejo de Ministros. Proyecto de Ley por la que se reconocen y amplian derechos y se establecen medidas en favor de quienes padecieron persecución o violencia durante la guerra civil y la dictadura. Madrid 2006. URL: http://www.mpr. es/ Documentos/memoria.htm (08/2007).

Véase www.elpais.com del 24 de mayo de 2007. 
víctimas? ¿Y por qué sus líderes se negaban a condenar un régimen que según todos los criterios del derecho internacional no podía sino considerarse un régimen injusto? Evidentemente, desde la derrota electoral de marzo del 2004 la cúpula dirigente del partido había adoptado una estrategia de oposición total contra el Gobierno. En el punto de mira estaba, además de la política del pasado y diversos otros proyectos socialistas, la cuestión de las responsabilidades de los atentados islamistas del 11 de marzo de 2004 en Madrid, los que al menos de forma indirecta habían contribuido a la victoria electoral de Zapatero. Los ataques contra el Gobierno abarcaron desde el reproche de haberlo utilizado para fines políticos hasta el intento de relacionar a sus perpetradores con la banda terrorista ETA $^{8}$ para así desacreditar la política del Gobierno hacia el País Vasco de encontrar una solución negociada. Un importante apoyo en esta dirección fue la Asociación de Víctimas del Terrorismo (AVT), que como representante de las víctimas del terror de ETA y de los atentados de Madrid funcionó al mismo tiempo como altavoz del Partido Popular en varias manifestaciones públicas contra la gestión del Gobierno. Bien es verdad que el mayor número de familiares de víctimas del 11-M se había sumado a asociaciones de tendencias izquierdistas. Pero la AVT - dirigida en este momento por su controvertido presidente Francisco José Alcaraz - había conseguido activar para los sectores conservadores el capital moral que significan las víctimas del terrorismo dando así una respuesta conservadora a la retórica victimista del movimiento por la memoria.

Aparte de la AVT, la reivindicación ética del movimiento por la memoria se vio contestada también por otro agente social: la Iglesia Católica. Hay que recordar que en el tardofranquismo gran parte de la jerarquía eclesiástica se había distanciado claramente del régimen culminando en 1971 en una declaración pública en la que se pidió perdón por el comportamiento de la Iglesia durante la Guerra Civil. Por el contrario, en un informe pastoral sobre la "actual situación en España" de noviembre de 2006, los obispos diagnosticaron con referencia a los planes del Gobierno "una utilización de la 'memoria histórica', guiada por una mentalidad selectiva" que volvía a abrir antiguas heridas. Y simultáneamente, el 28 de octubre de 2007 culminó la beatificación de

\footnotetext{
8 A lo largo de los más de dos años de investigación policial todas aquellas sospechas relacionadas con una presunta implicación de ETA en los atentados de Madrid se han resuelto de manera negativa. No obstante, hasta la fecha existen conocidos defensores de esta teoría como, por ejemplo, el controvertido locutor de la cadena COPE Federico Jiménez Losantos.
} 
un total de 498 "mártires del siglo XX" con una peregrinación a Roma de un gran grupo de católicos españoles de todo el país. Los mártires habían sido casi exclusivamente víctimas de las persecuciones religiosas durante la Guerra Civil, pero, tal y como se encargó de asegurar la Conferencia Episcopal, su beatificación no tenía nada que ver con la actual coyuntura memorialística. ${ }^{9}$

Bien es verdad que ante el protagonismo de la memoria de los vencidos se puede correr el peligro de olvidarse de las víctimas de la violencia revolucionaria en la zona republicana. Pero la recaída en una terminología "nacionalcatólica" sólo pone en evidencia el endurecimiento ideológico del catolicismo español, comenzado ya muchos años antes. Incapaces para el diálogo social, algunos sectores de la jerarquía eclesiástica se refugian en un activismo político que aspira - especialmente desde la toma de gobierno de los socialistas en 2004 - a flanquear la oposición total del Partido Popular. En el ámbito de las políticas del pasado, esta complicidad se hizo evidente hace poco en Valencia, ciudad gobernada por la alcaldesa popular, Rita Barberá. Aquí, una iniciativa ciudadana luchó en la primavera de 2006 durante semanas contra la decisión del Ayuntamiento de recubrir con nuevos nichos una amplia fosa anónima con víctimas de la represión franquista en el cementerio municipal. Finalmente, una sentencia judicial consiguió parar la terca decisión de la alcaldesa, que prácticamente en el mismo momento había cedido al Arzobispo de Valencia una antigua nave de fábrica cercana a la lujosa zona de la nueva Ciudad de las Artes y las Ciencias para que ahí se construyera un mausoleo destinado a los 226 valencianos asesinados durante la Guerra Civil "por el odio a la fe". ${ }^{10}$

No existe prueba que demuestre con más claridad el intento de polarizar el debate sobre el pasado que la instrumentalización de los muertos. Ahora bien, con respecto a la sociedad española hay que constatar que desde la Transición la Iglesia ha perdido gran parte de su antiguo peso y que su injerencia en la política diaria no es vista con buenos ojos por una gran mayoría de la población. Y tampoco corresponde con la opinión mayoritaria la provocadora actitud del Partido Popular como guardián de la herencia franquista. Sin embargo, distintas encuestas destacaron una y otra vez una sorprendente benevolencia de muchos ciudadanos frente a la dictadura. Son aspectos tan positivos como el milagro económico y el bienestar creciente de los años 60 y

9 Véase www.elpais.com del 27 de abril de 2007.

10 Al respecto véase El País del 2 de julio de 2007. 
70 los que influyen sobremanera en la percepción de la dictadura como un régimen con "cosas buenas y cosas malas". Y es precisamente esta benevolencia la que permite al Partido Popular apelar a los ámbitos católicos y de extrema derecha sin miedo de perder simpatías entre sus votantes del centro.

Para el propio Partido Popular el coqueteo con la herencia franquista corresponde en cierto modo con su propio origen social en algunos sectores reformistas del franquismo que hasta hoy se refleja como una continuidad sociológica en los círculos dirigentes del partido. La condena del franquismo como un régimen injusto contradiría, por tanto, las identidades personales y familiares de ciertos líderes del partido. Además, semejante posicionamiento iría en contra de la estrategia electoral de la formación pues ésta debería estar interesada en seguir integrando el margen ultraderechista del electorado. En cualquier caso, lo cierto es que desde la Transición ninguno de los partidos de extrema derecha existentes en España ha logrado ni por asomo una representación parlamentaria.

\section{Los herederos de la República: entre memoria y nostalgia}

Mientras que el intento de los socialistas de ganarse el apoyo de los conservadores se vio condenado al fracaso, en la izquierda se abrió un segundo frente contra el proyecto del Gobierno. Representantes de asociaciones y partidos criticaban que la proposición de ley se había quedado muy por debajo de sus exigencias. Así, el Gobierno pretendía esquivar la cuestión crucial de la anulación por ley de los miles de condenas políticas con la creación de una comisión de rehabilitación que carecería de competencias jurídicas. La rehabilitación de las víctimas sería por tanto un acto meramente simbólico que exigiría, además, una tramitación para cada caso individual. También se criticó que el Estado - a pesar de haber anunciado ayudas financieras y apoyo infraestructural para las exhumaciones de las fosas comunes - continuara dejando el asunto bajo la responsabilidad de agentes civiles y que por temor a conflictos políticos se renunciara a una retirada obligatoria de los símbolos franquistas en el espacio público de pueblos y ciudades en todo el país. ${ }^{11}$ Para Amnesty International, además, la verdadera problemática

${ }^{11}$ Para consultar los comentarios de los partidos y asociaciones véase www.elpais.com del 3 de agosto de 2006. 
radicaba en que la propuesta del Gobierno impedía la persecución jurídica y penal de los crímenes de lesa humanidad cometidos por la dictadura y que de este modo se perpetuaría la impunidad de los verdugos recogida en la Ley de Amnistía de 1977, por lo que la organización denunció el proyecto como una Ley de Punto Final. ${ }^{12}$

A pesar del carácter utópico de tal exigencia bajo las actuales circunstancias, algunas partes del movimiento por la memoria se unieron a este juicio. Pero a su vez, el motivo del rechazo no radicaba siempre en un auténtico compromiso con los derechos humanos. Aparte de la gran mayoría que en primer lugar busca esclarecimiento con respecto al destino de sus antepasados, el movimiento ha atraído también a muchos activistas políticos que intentan utilizar la coyuntura para otros fines. De manera distinta a la organización pionera de Emilio Silva, que se esfuerza por mantener una cierta neutralidad política, el Foro por la Memoria dirigido por José María Pedreño ha enlazado la recuperación de la memoria con objetivos explícitamente políticos. El motivo de esta estrategia es el intento de deslegitimar la Transición, propuesto públicamente hace algún tiempo por intelectuales de izquierda como Vicenç Navarro. ${ }^{13}$ Así, según Pedreño, "la Ley de Amnistía de 1977, y toda la legislación posterior que se apoyó en el espíritu de la misma, están impidiendo, en la actualidad, la evolución hacia una democracia avanzada". Y además, está convencido el presidente del Foro: "de que la Casa Real Española se encuentra detrás de todo impedimento para perseguir la impunidad del régimen franquista en nuestro país". ${ }^{14}$

Ahora bien, lo que hay que entender por "democracia avanzada" lo indica la nueva euforia que desde hace algún tiempo viene suscitando la Segunda República de los años 30 y que en ciertos círculos parece alimentar una demanda casi mesiánica a favor de una Tercera República. Momento de apogeo de este nuevo republicanismo fue el 75 aniversario de la proclamación de la Segunda República el 14 de abril de 2006. Si la historia republicana había sido durante mucho tiempo zona prohibida para la memoria posfranquista debido a su desastroso final, ahora y

12 Véase www.elmundo.es/elmundo/2006/11/16/espana/1163686411.html (11/2006). Como Ley de Punto Final se conoce generalmente la ley aprobada en 1986 durante el gobierno del presidente argentino Raúl Alfonsín en la que se decretaba el final de la persecución penal de todos los soldados y oficiales que habían participado en la violación de los derechos humanos durante la dictadura militar en Argentina.

13 Al respecto véase NAVARRO, Vicenç. Bienestar insuficiente, democracia incompleta. Barcelona: Ed. Anagrama, 2002, p. 209-216.

14 Véase PEDREÑO, José María. Recuperar la Memoria es luchar por la III República. URL: http://www.nodo50.org/foroporlamemoria/ (04/2005). 
por primera vez desde la Transición se le dedicaron en todo el país exposiciones y actos conmemorativos, en su mayoría privados. Y a pesar de los ataques desde la derecha, incluso el Gobierno socialista acabó viéndose obligado a una tímida rehabilitación de la Segunda República, refiriéndose a la misma como "la experiencia democrática más importante" y "el antecedente directo de la actual democracia". ${ }^{15}$ Pero si los socialistas pretendían honrar una época injustamente denigrada, la mayoría de las iniciativas particulares buscaba defenderla como alternativa a la Monarquía actual. De encuestas consecutivas sobre la preferencia acerca de la forma de Estado se desprende que ni siquiera una cuarta parte de la población española antepone la república a la Monarquía. Pero si se analizan los resultados según la edad de los encuestados, se aprecia una creciente inclinación por la república a medida que baja la edad. Así, en 2005, en el grupo de los más jóvenes de entre 18 y 25 años la preferencia republicana ascendía a un considerable $38 \% .^{16}$

Este nuevo republicanismo también ha echado raíces en el ámbito político. Así, desde hace algún tiempo el Partido Comunista - fuerza mayoritaria en la alianza de partidos de Izquierda Unida - muestra una clara voluntad de distanciarse al menos retóricamente de la Monarquía borbónica que se había aceptada al principio de la Transición con una amplia mayoría. La octava "tesis política", aprobada en el 17 Congreso del Partido Comunista en junio de 2005 reclamaba en este sentido "la reivindicación de su memoria [la de las víctimas del franquismo] y la rehabilitación de todos sus derechos vulnerados [como] una condición necesaria para que pueda superarse totalmente la situación de democracia otorgada". 17

\section{Conflictos identitarios y pasado reciente}

De acuerdo con el intento de instrumentalizar la memoria para fines políticos está también Esquerra Republicana de Catalunya, un partido histórico que forma parte del en general muy diferente espectro político en Cataluña. Durante muchos años Esquerra estaba ubicada al margen de la política catalana, hasta conseguir en el año 2003 una

15 Véase $A B C$ del 23 de junio de 2006.

16 Véase los resultados de la encuesta en www.elmundo.es del 20 de noviembre de 2005.

17 Véase la página del Partido Comunista. URL: http://www.pce.es/pcei_pl.php?id=512 (07/2008). 
victoria histórica con un $16 \%$ de los votos lo que le permitió formar parte del nuevo Ejecutivo regional compuesto de tres partidos de izquierda. Las más recientes intentos de deslegitimizar la Monarquía desde Cataluña están, por tanto, impregnados de un fuerte tono catalanista que corresponde con el tradicional conflicto de la política española entre el centro castellano y algunas regiones periféricas como Cataluña o el País Vasco. Como si la Guerra Civil no hubiera tenido raíces propias en Cataluña, los republicanos exigieron con relación al fusilamiento en 1940 de su antiguo presidente Lluís Companys ${ }^{18}$ una excusa formal del Gobierno central. Y poco después, en 2005, Esquerra volvió a repetir esta demanda aunque esta vez debía ser el Rey, por su papel como "la rótula entre la dictadura y el Estado democrático", el que debiera pedir disculpas. ${ }^{19}$ El Gobierno de Zapatero no pudo sino dar a estas peticiones una negativa rotunda que en esta ocasión se hallaba en plena consonancia con el Partido Popular. ${ }^{20}$

La radicalización del discurso nacionalista en Cataluña debida a la participación de Esquerra en el gobierno de la Generalitat coincide con el estridente renacimiento de un nacionalismo español que tras años de descrédito a causa de la experiencia franquista volvió a manifestarse especialmente a partir de la victoria electoral conservadora en 1996. Un auténtico choque de nacionalismos se ha presenciado recientemente con relación a los "papeles de Salamanca", un conjunto de documentación histórica procedente de Cataluña que junto a otros documentos de partidos e instituciones de la Segunda República se encontraba desde 1939 en el Archivo de la Guerra Civil de Salamanca. En un primer momento este archivo sirvió al régimen franquista como fuente de información acerca de sus enemigos para así sistematizar la represión política de la posguerra. Sin embargo, durante la Transición el archivo llegó a convertirse en el centro de investigación más importante sobre la historia de la Guerra Civil. Dado que el archivo también conserva

${ }^{18}$ Durante la guerra Lluís Companys era presidente del gobierno catalán (Generalitat). Tras la caída de Cataluña, Companys huyó a Francia, pero cayó en manos de la Gestapo tras la victoria alemana sobre este país. Poco después fue puesto a disposición del Gobierno franquista. De vuelta en España, fue condenado a muerte por un tribunal militar, acusándole de "rebelión". El 15 de octubre de 1940 se ejecutó la sentencia en el tristemente famoso castillo de Montjuïc en Barcelona. Véase al respecto BRINKMANN, Sören. Katalonien und der Spanische Bürgerkrieg. Berlín: Ed. Tranvía, 2007.

19 Véase El País del 29 de septiembre de 2004, así como www.elmundo.es del 18 de noviembre de 2005.

${ }^{20}$ Véase Europa Press del 14 de mayo de 2004 y www.elmundo.es del 18 de noviembre de 2005. 
documentos relacionados con el autogobierno catalán de los años 30, éste había solicitado en los años 70 la devolución de este acervo. El primer acuerdo de 1983 preveía poner a disposición de los catalanes copias de los originales. Pero la tardanza en su aplicación dio lugar a que el Gobierno de Madrid, tras varias quejas de Barcelona, decidiera en 1995 devolver los documentos originales. No obstante, la victoria electoral del Partido Popular un año después desplazó las simpatías del Gobierno español a favor del también conservador gobierno autonómico de Castilla y León, por lo cual se retiró la decisión del anterior Ejecutivo.

La continuación de esta curiosa querella estuvo determinada por el nuevo cambio de gobierno en 2004 así como por la sorprendente disposición en ambas regiones de indignarse colectivamente. En Cataluña la "Comissió de la Dignitat", una asociación cívica, movilizó a las masas, ante lo cual el Gobierno de Zapatero decidió recurrir al peritaje de una comisión de expertos. Esta, finalmente, se expresó en su mayoría a favor de la devolución de los documentos, lo que provocó reacciones histéricas en Castilla y León. Mientras el alcalde popular de Salamanca recurrió en la primavera de 2005 al Defensor del Pueblo y hasta a la UNESCO, el gobierno autonómico intentaba blindar el archivo mediante la ley y a pesar de su pertenencia al patrimonio cultural del Estado español. El apogeo de la excitación colectiva se alcanzó con una manifestación de protesta convocada en Salamanca - ciudad de 160.000 habitantes - que en junio de 2005 arrastró a las calles a más de 80.000 participantes. E innumerables pancartas con la inscripción "España y Archivo = Unidad" dejaban poca duda sobre la voluntad de los responsables de articular un rechazo categórico frente a Cataluña y el nacionalismo catalán. ${ }^{21}$

Esta carga simbólica atribuida a un centro de investigación provoca precisamente a llevar la contraria. Porque contemplando esta institución desde su finalidad original, se impone la conclusión de que su equiparación con la unidad nacional no puede sino referirse a la España autoritaria y exclusivamente castellana del dictador Francisco Franco. Resulta algo más fácil entender la magnitud de la protesta en Salamanca si se la contempla como parte del debate acerca del nuevo Estatuto de autonomía catalán que se desarrollaba casi paralelamente a las negociaciones sobre la devolución de los famosos papeles. Ya en 2003, el candidato socialista a la Presidencia del Gobierno había asegurado en Barcelona su apoyo a una reforma del estatuto. Pero el borrador elaborado por el tripartito en septiembre de 2005 contenía

${ }^{21}$ Véase El País del 12 de junio de 2005. 
varios pasajes de dudosa constitucionalidad. La consecuencia de esto no fue solamente un largo y conflictivo debate parlamentario sino también una intensa movilización anticatalana en el país, orquestada principalmente por el Partido Popular, y en la que el alboroto alrededor de los "papeles de Salamanca" encajaba a la perfección. En septiembre de 2005, sin embargo, el Congreso de los Diputados resolvió el asunto mediante una ley de devolución..$^{22}$ El debate del Estatuto catalán, por su parte, finalizó medio año después con la aprobación del mismo en contra de los votos del Partido Popular. Muy descontento con el resultado final quedó también Esquerra Republicana que expresó su protesta mediante la abstención de su grupo parlamentario. Y cuando los republicanos procedieron incluso a llamar a sus seguidores a votar en contra del texto en el referendum de junio de 2006, se desató el escándalo final que acabaría con la ruptura del tripartit.

Las elecciones anticipadas en Cataluña a finales de 2006 dieron como resultado la repetición del tripartit. Y poco después de haber formado el nuevo gobierno, éste aumentó otra vez la presión con respecto a las políticas del pasado. Una de las primeras medidas del gobierno catalán consistió en retomar un proyecto presentado hacía dos años de un centro de documentación e instrucción acerca del pasado reciente. El objetivo central del llamado Memorial Democràtic era en palabras de Joan Saura, presidente de los ecosocialistas y conseller responsable, la representación y divulgación de la historia catalana desde la Segunda República, prestándose especial atención a la represión franquista y a la lucha por las libertades democráticas. Poco después, la Generalitat anunció además que prepararía una proposición de ley sobre la apertura de las más de 170 fosas anónimas de la Guerra Civil identificadas en Cataluña. ${ }^{23}$ La iniciativa se apoyaba en un artículo del

${ }^{22}$ La devolución de los documentos catalanes fue concluida definitivamente en la primavera de 2008. Véase El País del 28 de mayo de 2008. Peticiones semejantes surgidas desde otras comunidades fueron rechazadas por la Ministra de Cultura, Carmen Calvo, que justificó la excepción catalana por la calidad de los documentos, pues entre otras cosas en ellos se certifica la existencia singular de Cataluña como autonomía histórica. Véase El País del 16 de septiembre de 2005.

${ }^{23}$ Un recuento definitivo de la Generalitat realizado en primavera de 2008 llegó a una cifra de 179 fosas en el territorio de la comunidad. Se calcula que en esas fosas comunes están enterradas aproximadamente 9.000 personas. La mayoría de los enterrados eran soldados del ejército republicano muertos durante la conquista de Cataluña entre el otoño de 1938 y febrero de 1939. Por tanto, aproximadamente la mitad de las fosas se ecuentran en cementerios municipales. Véase www.elperiodico. com del 18 de marzo de 2007 así como la página de la Generalitat. URL: http:// www10.gencat.net (07/2008). 
nuevo Estatuto de autonomía que permite a la Generalitat rehabilitar "a todos los ciudadanos perseguidos por defender la democracia y el gobierno autonómico de Cataluña". Al mismo tiempo, estos avances también se dirigían a aumentar la presión al Congreso en Madrid para que diera un nuevo impulso a las estancadas negociaciones sobre la ley de reparación proyectada por el Gobierno socialista.

\section{La Ley de Memoria - una reparación tardía}

Es sin duda a causa de la radicalización de posiciones desde la izquierda y la derecha que el Gobierno continuara operando con gran cautela tras haber presentado en julio de 2006 su proposición de ley. Sin embargo, entre la tormenta de críticas casi no se advirtieron las reacciones moderadas provenientes de los partidos nacionalistas moderados que iban a jugar un papel clave a la hora de obtener una mayoría suficiente en el Congreso. Al contrario de los populares, representantes del Partido Nacionalista Vasco y de Convergència i Unió habían anunciado su voluntad de presentar sólo enmiendas parciales al texto lo que aseguraría la tramitación del proyecto. ${ }^{24} \mathrm{Y}$ efectivamente, el 14 de diciembre de 2006, casi medio año después de su presentación, el proyecto logró superar la primera votación mientras que las enmiendas a la totalidad lanzadas por el Partido Popular y por Esquerra Republicana fracasaron. Quedaba claro así que como interlocutores del Gobierno sólo quedaban Izquierda Unida y los nacionalistas catalanes y vascos. $\mathrm{Y}$ especialmente estos últimos aumentaron entonces el precio de su apoyo, exigiendo - en concordancia con Izquierda Unida - entre otras cosas la anulación definitiva de los juicios sumarísimos franquistas. ${ }^{25}$ En abril de 2007, la opinión pública fue sorprendida con la noticia de que socialistas e Izquierda Unida habían llegado a un acuerdo. La fórmula de compromiso preveía declarar "ilegítimos" estos juicios, evitándose de este modo una anulación general (cuyas complicaciones jurídicas se temía), mientras que se abrió también un camino a posibles rehabilitaciones en casos concretos lo que parecía satisfacer las demandas de familiares y asociaciones. ${ }^{26}$

${ }^{24}$ Véase Avui del 29 de julio de 2006. El Partido Nacionalista Vasco y Convergència i Unió son partidos de orientación nacionalista y democristiana cuyo radio de acción está limitado a sus respectivas regiones. Sin embargo, ambos disponen de una representación en el parlamento español lo que les permite con frecuencia jugar un papel crucial dada la frecuente situación de minoría de los gobiernos centrales.

25 Véase www.elpais.com del 13 de diciembre de 2006.

${ }^{26}$ Véase www.elpais.com del 19 de abril de 2007. 
Sin embargo, para llegar a una mayoría parlamentaria se necesitaba también el apoyo de los partidos nacionalistas lo que hizo necesario aún más concesiones en el proyecto de ley. Especialmente Convergència i Unió criticaba también en esta ocasión la falta de equilibrio político, solicitando por lo tanto una mención explícita de la violencia anticlerical en el bando republicano mientras que los nacionalistas vascos hacían depender su apoyo de la devolución de sus "papeles de Salamanca" según el ejemplo catalán. ${ }^{27}$ Lo que entonces siguió fueron intensas negociaciones contra reloj que a principios de octubre - poco antes de finalizar la legislatura - concluyeron en un entendimiento de todas las partes implicadas que iba a garantizar la votación final de la ley el 31 de octubre de 2007.

En plena oposición permaneció no sólo el Partido Popular sino también Esquerra Republicana que por motivos diametralmente opuestos tachó la ley de "fraude". Y con esta actitud los catalanistas radicales coincidían con una parte considerable de las asociaciones cívicas y de derechos humanos que como Amnesty International reconocían como mucho una "mejora gradual" con respecto a los derechos de las víctimas. ${ }^{28}$ No obstante, lo cierto es que muchos de los críticos de la ley se contarían finalmente entre sus mayores beneficiarios. Y en cualquier caso también es verdad que gran parte de las reivindicaciones planteadas por el movimiento de la memoria quedan recogidas en esta ley: así, por primera vez en la historia posfranquista la dictadura es declarada un régimen injusto; las indemnizaciones financieras se amplian a prácticamente todos los grupos no considerados hasta la fecha, incluidos los homosexuales; se facilita el acceso a los archivos que documentan la represión franquista; el Estado se compromete a apoyar activamente la exhumación de los "desaparecidos"; todos los símbolos del régimen todavía existentes en edificios públicos habrán de ser retirados ${ }^{29}$; se

${ }^{27}$ De manera similar al caso de la Generalitat republicana, la documentación archivada en Salamanca contiene documentos relacionados con la autonomía vasca de los años 30, cuya devolución había sido definitivamente descartada por el Gobierno al concluir las negociaciones con Cataluña para evitar la progresiva desintegración de este Archivo.

28 Véase www.elpais.com del 19 de octubre de 2007.

${ }^{29}$ La votación definitiva aportó una pequeña modificación en este aspecto. Así, en el proyecto de ley se había previsto originalmente obligar también a las instituciones privadas a retirar toda la simbología que recordara al franquismo bajo amenaza de reducir las subvenciones estatales. Esta decisión apuntaba directamente a la Iglesia Católica, responsable de las numerosas placas conmemorativas de "los caídos por Dios y por España". Sin embargo, el pasaje fue suprimido debido a la intervención de Convergència i Unió. 
ampliará el Archivo de la Guerra Civil de Salamanca con un centro de documentación y estudio; el Valle de los Caídos, el mausoleo monumental de Franco al norte de Madrid, queda clausurado para todo tipo de actos políticos y se podrán recurrir los juicios sumarísimos ante los tribunales competentes. ${ }^{30}$

De este modo, no hay ninguna duda de que la Ley de Memoria represente un serio cambio de parádigma en el tratamiento oficial del pasado reciente. Sin embargo, a finales del año 2008 resulta difícil pronosticar los efectos a largo plazo que este cambio de rumbo en las políticas del pasado tendrá sobre la conciencia histórica de la sociedad española. Cierto parece únicamente que ante la nueva victoria de los socialistas en las elecciones generales de marzo de 2008 el Gobierno dispone por lo menos de una legislatura entera para poner en marcha las medidas propuestas por la nueva norma. Sin embargo, antes de que actuara el Ejecutivo, el primer efecto de la Ley de Memoria cobró forma con la intervención del juez de la Audiencia Nacional, Baltasar Garzón, famoso en España y fuera de ella por una serie de procesos espectaculares contra el crimen organizado, la corrupción política y, especialmente, por el notorio orden de arresto contra el exdictador chileno Augusto Pinochet en 1999. En septiembre de 2008 y a base de varias denuncias por parte de una docena de asociaciones cívicas Garzón comenzó las diligencias para averiguar si es competente de investigar los múltiples casos de desapariciones causadas por la sublevación militar de 1936.

La actuación del juez levantó muchas esperanzas dada la sorprendente perspectiva de que el propio régimen de Franco iría a ser juzgado por las autoridades jurídicas del Estado posfranquista. Y de hecho Garzón no dudó en proseguir con la tarea al pedir informaciones del Estado y de la Iglesia católica acerca de la identidad de más de 90.000 muertos causados presuntamente por la represión franquista. A mediados de octubre las diligencias culminaron con un auto en el que Garzón se declaró competente a investigar el paradero de 114.266 personas desaparecidas y con la que ordenó la apertura de 19 fosas anónimas, entre ellas la del escritor Federico García Lorca. Ahora bien, la clave del auto del juez estribaba en atribuir al dictador Francisco Franco y a otros 34 dirigentes de la sublevación militar un "plan de exterminio sistemático" contra sus oponentes, lo que le permitió a

${ }^{30}$ La versión final del proyecto de ley aprobada por el Congreso el 31 de octubre de 2007 fue publicada en el Boletín Oficial del Estado del 27 de diciembre de 2007. 
Garzón considerar las purgas y represiones de los vencedores como crímenes contra la humanidad y por tanto imprescriptibles. ${ }^{31}$

El hecho de que un representante de la más alta autoridad penal del país preguntara por las responsabilidades jurídicas de los crímenes del régimen y así pusiera en duda la impunidad de los verdugos, recogida en la Ley de Amnistía de 1977, provocó reacciones histéricas en algunos sectores del Partido Popular. Sin embargo, las dudas jurídicas suscitadas con respecto a la declaración de competencia del juez Garzón no estaban solamente motivadas por razones políticas. Poco después de publicar la resolución Javier Zaragoza, el fiscal jefe de la Audiencia Nacional, se opuso categóricamente al auto de Garzón, acusándole de querer abrir una "inquisición general" de la guerra civil y de la dictadura, no amparada, según él, por la Constitución vigente. La pugna jurídica desatada por la actuación de Zaragoza se decidió finalmente en la Sala de lo Penal de la misma Audiencia Nacional que a finales de noviembre concluyó que Garzón no era competente para investigar el golpe de estado franquista dado que este delito no se encuentra entre los crímenes atribuidos a esta institución. ${ }^{32}$

Con el cierre de la vía judicial, que llegó casi tan repentinamente como su apertura, la responsabilidad por el esclarecimiento del pasado reciente recae definitivamente en el Gobierno. Y aunque el Partido Popular tras su nueva derrota electoral llegó a reblandecer su discurso oposicionista, el Gobierno socialista dejó pasar once meses desde la puesta en vigor de la Ley de Memoria hasta que diera las primeras señas de su voluntad de cumplirla. Así, sólo a finales de octubre el Consejo de Ministros aprobó tres decretos que se refieren a la concesión de la nacionalidad española a los hijos y nietos de los exiliados, a la preparación de un protocolo de actuación científica para los casos de exhumación de desaparecidos y a la creación de una comisión de expertos encargada de la retirada de los símbolos franquistas en el espacio público.

Con todo, a finales del año 2008, el primer efecto tangible de las nuevas políticas del pasado se dejó ver únicamente en el distante recinto monumental del Valle de los Caídos: ahí, por primera vez la tradicional misa en honor al Caudillo el 20 de noviembre se llevó a cabo entre un grupo muy reducido de participantes, mientras que un amplio despliegue de la Guardia Civil velaba sobre el cumplimiento del artículo 16 de la ley que prohibe la exaltación de la Guerra Civil y del franquismo. ${ }^{33}$

31 Véase www.elpais.com del 17 de octubre de 2008.

32 Véase www.elmundo.es del 20 de octubre de 2008 así como www.elpais.com del 29 de noviembre y del 5 de diciembre de 2008.

33 Véase www.elpais.com del 21 de noviembre de 2008. 